DOI 10.37882/2223-2974.2020.12.13

\title{
ЭКОНОМИЧЕСКИЙ ПОТЕНЦИАЛ ХОЗЯЙСТВУЮЩЕГО СУБЪЕКТА, КАК ИНТРОСПЕКЦИЯ СОВРЕМЕННОЙ ЭКОНОМИЧЕСКОЙ РЕАЛЬНОСТИ
}

\section{ECONOMIC POTENTIAL OF AN ECONOMIC ENTITY AS AN INTROSPECTION OF MODERN ECONOMIC REALITY \\ R. Yelshibayev \\ M. Darzhanova \\ S. Bolatkyzy}

Summary: Relevance.

Economic potential is a complex systemic phenomenon that is complex and multi-component in nature. With the change in the economic formation of modern society, the forms and content of the phenomenon are transformed, which emphasizes the need for scientific research in accordance with the changed system of modern management.

Object of research. Economic potential as an integral property of complex dynamic systems.

Subject of research. Economic potential as a phenomenon and event in the economic activity of the subject of economic relations.

Purpose of research. It consists in a descriptive true description of the economic potential as an inherent phenomenon of the economic life of society.

Research problem. They consist in considering the phenomenon of economic potential within the framework of economic activity of the subject of economic relations, revealing the form and content of the phenomenon in the categories of economic knowledge.

Research methodology. Phenomenological research methods are used, which are expressed in theoretical-heuristic and scientific-applied methods of cognition of the phenomenon under study.

Research result. They are expressed in the disclosure of the forms and content of the phenomenon of economic potential with the unification of the phenomenon within the field of economic knowledge.

Accepted designations and abbreviations. Economic potential (EP), production potential (PP), investment potential (IP), financial potential (FP), innovation potential (Ipinn).

Keywords: investment potential, value added, innovation potential, economic activity, financial potential, production potential.
Елиибаев Ракымжан Камытбекулы К.э.н., ассочированный профессор, Университет Нархоз, Республика Казахстан, г. Алматы rakymzhan.yelshibayev@bk.ru

Даржанова Мунира Шамсутдиновна К.э.н., ассочиированный професссор, Каспийский университет, Республика Казахстан, г. Алматы mun46@mail.ru

Болатқызы Салтанат

К.э.н., Алматинский технологический уиверситет, Республика Казахстан, г. Алматы saltab@mail.ru

Аннотация: Актуальность.

Экономический потенциал - сложный системный феномен, по природе своей являющийся комплексным и многосоставным. С изменением экономической формации современного общества, формы и содержание феномена преобразуются, что подчёркивает необходимость научных изысканий в соответствии с изменившейся системой современного хозяйствования.

0бъект исследования. Экономический потенциал, как неотъемлемое свойство сложных динамических систем.

Предмет исследования. Экономический потенциал, как явление и событие в хозяйственной деятельности субъекта экономических отношений.

Цель исследования. Состоит в дескриптивном истинном описании экономического потенциала, как ингерентного феномена хозяйственной жизни общества.

Задачи исследования. Заключаются в рассмотрении феномена экономического потенциала, в рамках хозяйственной деятельности субъекта экономических отношений, раскрытии формы и содержания явления в категориях экономического знания.

Методология исследования. Используются феноменологические методы исследования, выражающиеся в теоретико-эвристическом и научно - прикладном методах познания, исследуемого феномена.

Результаты исследования. Выражаются в раскрытии форм и содержания феномена экономического потенциала с унификацией феномена в рамках области экономического знания.

Принятые обозначения и сокращения. Экономический потенциал (ЭП), производственный потенциал (ПП), инвестиционный потенциал (ИП), финансовый потенциал (ФП), инновационный потенциал (ИПннн).

Ключевые слова: инвестиционный потенциал, добавленная стоимость, инновационный потенциал, хозяйственная деятельность, финансовый потенциал, производственный потенциал.

меняться в зависимости от контекста прикладного применения. Как уже было отмечено, цель нашего исследования состоит в дескриптивном истинном описании феномена, который позволит унифицировать методическую основу исследования. Для того чтобы придти к 
единообразию денотативного значения понятия экономический потенциал, необходимо для целей исследования представить дефиницию этого понятия. Как уже было сказано, экономический потенциал многосоставной феномен, и прежде чем унифицировать категориаль но-понятийный аппарат, необходимо раскрыть состав феномена. Деятельность хозяйствующего субъекта состоит, в общем виде, из трёх компонент: производственная, инвестиционная и финансовая. В условиях современной системы хозяйствования появилась новая компонента хозяйственной деятельности - инновационная, которая обусловлена постиндустриальным этапом развития общества. Таким образом, можно утверждать, экономический потенциал, в общем виде, состоит из 4-х компонент частных случаев потенциала - производственного (ПП), инвестиционного (ИП), финансового (ФП) и инновационного (ИПинн) (рисунок 1). При этом компоненты экономического потенциала в частном виде также требуют содержательного теоретического осмысления.

Последовательно и содержательно разберём элементы экономического потенциала и сам феномен для реализации целей исследования.

\section{Основная часть}

Представим определения, что подразумевается под частными видом потенциала.

Производственный потенциал (авторское определение) - разница между максимальной производственной мощностью и фактической производственной мощностью в конкретный момент времени, при условии максимально возможной интенсивной и экстенсивной загрузки совокупности факторов производства, имеющихся в распоряжении хозяйствующего субъекта в момент оценки.

Инвестиционный потенциал (авторское определение) - разница между справедливой стоимостью хозяйствующего субъекта в конкретный момент времени, при сложившихся условиях хозяйствования и справедливой стоимостью на момент оценки при условии реализации производственного и финансового потенциала субъекта предпринимательства. Тут следует отметить, что инвестиционный потенциал условно «внешнее» свойство системы, так как характеризуется приращением инвестиционной стоимости во времени, которая по природе своей внешняя. Можно согласиться, что [2]: «инвестиционный потенциал - совокупность всех возможностей получения добавленной стоимости на вложен-

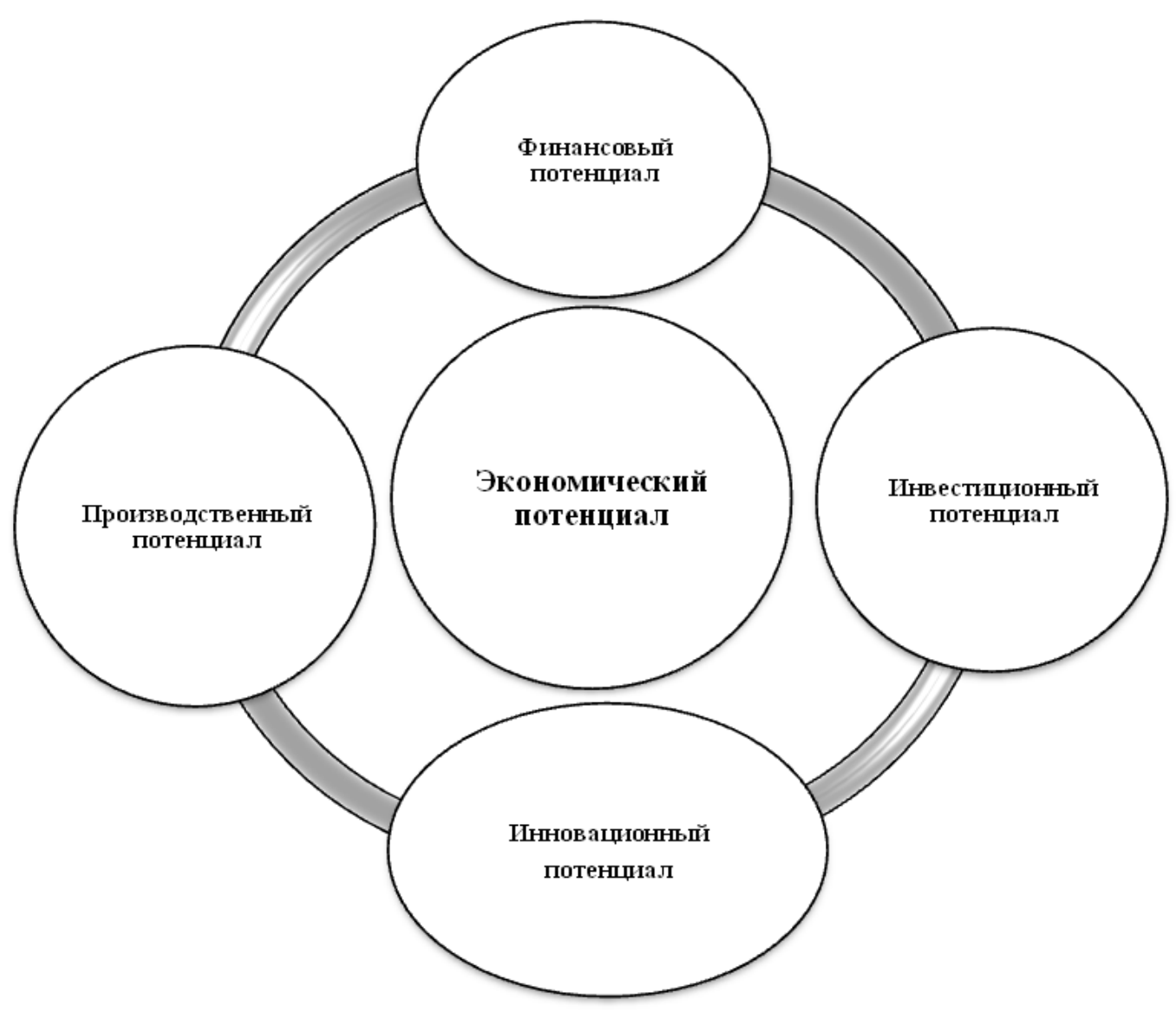

Рис. 1. Комплексная цикл-схема компонентов экономического потенциала. 
ные ресурсы, исходя из количественных и качественных показателей объекта инвестирования». Вложения, которые внешние по отношению к хозяйствующему субъекту возможны только при наличии или реализации финансового и производственного потенциала. Действительно, следуя формальной логике: какой смысл инвестору вкладывать денежные средства (или их эквиваленты), если производство стагнирует (или сокращается), или присутствуют значительные финансовые риски.

Финансовый потенциал (авторское определение) - разница между уровнем и структурой финансовых ресурсов при условии обеспечения реализации производственного потенциала и уровнем, и структурой финансовых ресурсов, сложившимися на момент оценки.

Из приведённых определений следует, что частные виды потенциала представляют собой горизонтальную структуру с принципом соподчинённости [1] в последовательности элементов (рисунок 2).
На рисунке 2 отображена последовательность и структура соподчинения элементов экономического потенциала, но отсутствует инновационный потенциал и причина этому факту, следующая: инновационный потенциал не является обязательным атрибутом экономического потенциала, в отличии от финансового, производственного и инвестиционного потенциала. Действительно, если хозяйствующий субъект не проявляет инновационную активность, то факт отсутствия инновационного потенциала очевиден. Отсюда следует, что инновационный потенциал не характеризуется обязательным свойством наличия в характеристике экономического потенциала, его присутствие обусловлено наличием инновационной активности. Дадим определение, что такое инновационный потенциал хозяйствующего субъекта.

Инновационный потенциал (авторское определение) - действительно обусловленная возможность создания инноваций, в виде инновационного продукта, как результата хозяйственной деятельности субъекта

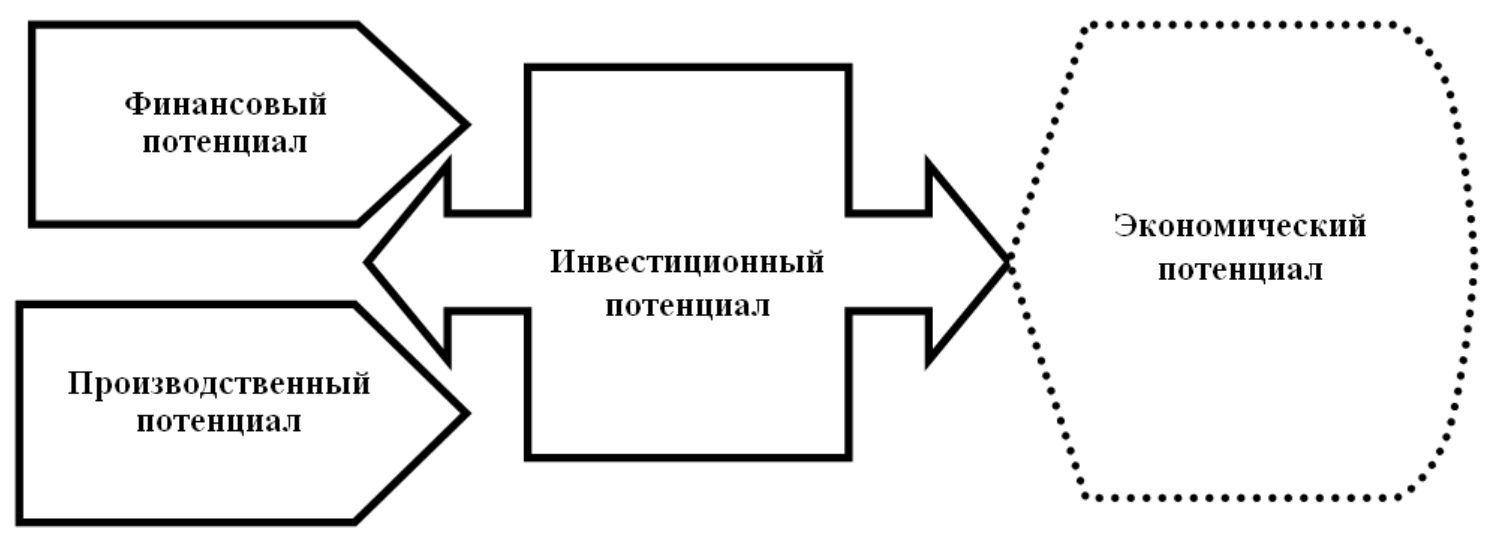

Рис. 2. Последовательность и соподчинённость элементов экономического потенциала.

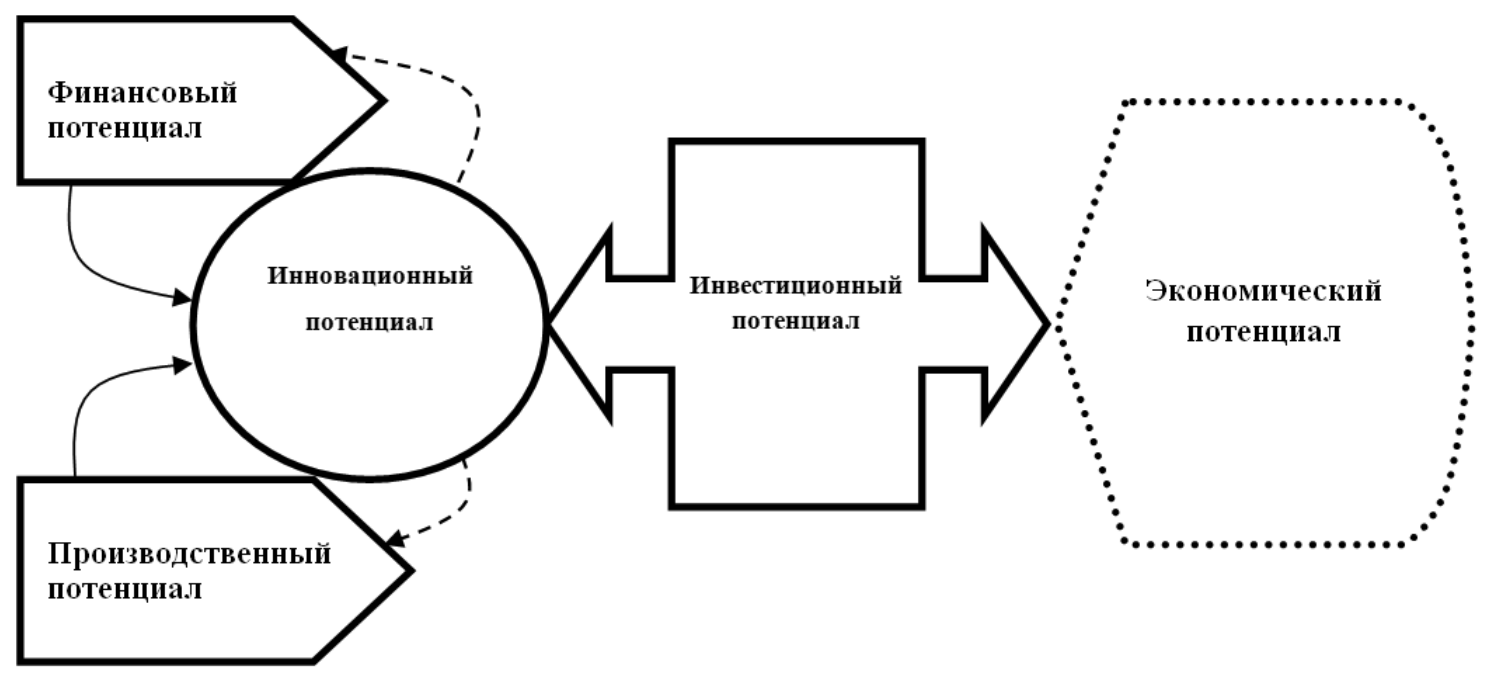

Рис. 3. Последовательность и соподчинённость элементов экономического потенциала при наличии инновационной активности. 
экономических отношений, не зависимо от формы проявления (овеществлённая или идейная), при условии его воспроизводства.

Тогда последовательность элементов ЭП, представленная на рисунке 2, будет иметь другой вид (рисунок 3).

Учитывая приведённые выше определения элементов ЭП, представим комплексное определение, такой категории, как экономический потенциал.

Экономический потенциал (авторское определение) - разница между экономическим результатом хозяйствования при условии реализации финансового, производственного, инвестиционного и, в частном случае, инновационного потенциала и фактическим уровнем экономического результата хозяйствования на момент оценки.

Говоря об оценке экономического потенциала, необходимо отметить, что комплексный показатель ЭП представляет из себя аддитивную сумму элементов ФП, ПП, ИП, ИП инн, то есть формула 1:

$$
\text { ЭП=ФП+ПП+ИП+ИПинн }
$$

Где элементы ФП, ПП, ИП, ИПинн - определения представлены выше.

Представим в табличной форме исходные данные для расчёта комплексного показателя ЭП.

Таблица 1.

Исходные данные для расчёта комплексного показателя ЭП

Сводная таблица исходных данных для расчёта ЭП

\begin{tabular}{|c|c|}
\hline \multicolumn{2}{|c|}{ Сводная таблица исходных данных для расчёта ЭП } \\
\hline Показатели хозяйствующего субъекта: & Тыс. тг. \\
\hline S (Выручка) & \\
\hline - Себестоимость & \\
\hline = ЕВІТ (Валовая прибыль) & \\
\hline - Коммерческие расходы & \\
\hline -Управленческие расходы & \\
\hline+ /-Прочие Доходы/Расходы & \\
\hline$=$ Прибыль от реализации & \\
\hline Амортизационные отчисления & \\
\hline = ЕВІтDА & \\
\hline - Налог на прибыль & \\
\hline$=$ Е (Чистая прибыль) & \\
\hline
\end{tabular}

Сводная таблица исходных данных для расчёта ЭП

\begin{tabular}{|c|c|}
\hline \multicolumn{3}{|c|}{ Сводная таблица исходных данных для расчёта ЭП } \\
\hline P (Стоимость всех обыкновенных акций) & \\
\hline +долговые обязательства (СL) & \\
\hline - денежные средства и их эквиваленты & \\
\hline = EV (Справедливая стоимость компании) & \\
\hline Суммарные активы & \\
\hline - Нематериальные активы + Гудвилл & \\
\hline - Долговые обязательства & \\
\hline = В (Чистые активы) & \\
\hline СА (Оборотные активы) & \\
\hline Показатели фактического уровня оценки \\
\hline EV/EBITDA & \\
\hline$E V / S$ & \\
\hline P/E & \\
\hline P/S & \\
\hline P/B & \\
\hline ROA=E/B & \\
\hline ROS=E/S & \\
\hline & \\
\hline
\end{tabular}

Имея исходные данные (таблица 1) мы можем провести сравнительную оценку1

Тогда имея фактический уровень показателей, мы можем провести сравнительную экономическую оценку (таблица 2).

Таблица 2.

Сводная таблица данных для расчёта ЭП Сводная таблица для расчёта ЭП

\begin{tabular}{|c|c|}
\hline $\begin{array}{c}\text { Показатели хозяйствующего } \\
\text { субъекта (факт): }\end{array}$ & $\begin{array}{c}\text { Показатели хозяйствующего } \\
\text { субъекта (потенциал): }\end{array}$ \\
\hline S (Выручка) & S $_{n}$ (Выручка) \\
\hline - Себестоимость & - Себестоимость \\
\hline = EBIT (Валовая прибыль) & $=$ EBIT $_{n}$ (Валовая прибыль) \\
\hline - Коммерческие расходы & - Коммерческие расходы \\
\hline - Управленческие расходы & - Управленческие расходы \\
\hline +/-Прочие Доходы/Расходы & +/- Прочие Доходы/Расходып \\
\hline = Прибыль от реализации & $=$ = Прибыль от реализации \\
\hline + Амортизационные отчисления & + Амортизационные отчисления \\
\hline$=\mathrm{EBITDA}$ & $=$ EBITDA $_{n}$ \\
\hline - Налог на прибыль & - Налог на прибыль п \\
\hline = E (Чистая прибыль) & $=\mathrm{E}$ (Чистая прибыль) \\
\hline
\end{tabular}

1 Необходимо иметь в виду, что представленные табличные данные фактического уровня оценки количественно по показателям могут быть (уместно отметить - должны) скорректированы ситуативно. 


\begin{tabular}{|c|c|}
\hline \multicolumn{2}{|c|}{ Сводная таблица для расчёта ЭП } \\
\hline $\begin{array}{c}\text { P (Стоимость всех обыкновенных } \\
\text { акций) } \\
\end{array}$ & $\begin{array}{c}\text { P (Стоимость всех обыкновенных } \\
\text { акций })_{n}\end{array}$ \\
\hline +долговые обязательства (CL) & +долговые обязательства (CL) п \\
\hline $\begin{array}{c}\text { - денежные средства и их эквива- } \\
\text { ленты }\end{array}$ & $\begin{array}{l}\text { - денежные средства и их эквива- } \\
\text { ленты }_{n}\end{array}$ \\
\hline $\begin{array}{c}=\mathrm{EV} \text { (Справедливая стоимость } \\
\text { компании) }\end{array}$ & $\begin{array}{c}=\mathrm{EV}_{n} \text { (Справедливая стоимость } \\
\text { компании) }\end{array}$ \\
\hline Суммарные активы & Суммарные активы \\
\hline $\begin{array}{c}\text { - Нематериальные активы + } \\
\text { Гудвилл } \\
\end{array}$ & $\begin{array}{l}\text { - Нематериальные активы }+ \\
\text { Гудвилл } \\
\end{array}$ \\
\hline - Долговые обязательства & - Долговые обязательства \\
\hline = В (Чистые активы) & $=B_{n}$ (Чистые активы) \\
\hline СА (0боротные активы) & CA (0боротные активы) \\
\hline $\begin{array}{c}\text { Показатели фактического } \\
\text { уровня оценки }\end{array}$ & $\begin{array}{c}\text { Показатели уровня оценки при } \\
\text { реализации ЭП }\end{array}$ \\
\hline EV/EBITDA & EV/EBITDA \\
\hline $\mathrm{EV} / \mathrm{S}$ & $\mathrm{EV} / \mathrm{S}_{\mathrm{n}}$ \\
\hline $\mathrm{P} / \mathrm{E}$ & $P / E_{n}$ \\
\hline $\mathrm{P} / \mathrm{S}$ & $\mathrm{P} / \mathrm{S}_{\mathrm{n}}$ \\
\hline$P / B$ & $P / B_{n}$ \\
\hline
\end{tabular}

\begin{tabular}{|l|l|}
\hline \multicolumn{2}{|c|}{ Сводная таблица для расчёта ЭП } \\
\hline $\mathrm{ROA}=\mathrm{E} / \mathrm{B}$ & $\mathrm{ROA}_{\mathrm{n}}=\mathrm{E} / \mathrm{B}$ \\
\hline $\mathrm{ROS}=\mathrm{E} / \mathrm{S}$ & $\mathrm{ROS}=\mathrm{E} / \mathrm{S}$ \\
\hline
\end{tabular}

Таким образом, хозяйствующий субъект для оценки своего экономического потенциала или заинтересованное лицо в табличной форме в виде цифровой модели могут рассчитывать элементы ЭП и комплексный показатель ЭП для целей оценки.

\section{Выводы}

В данном исследовании представлены дефиниции феномена экономического потенциала, с целью раскрытия содержательных характеристик категориально - понятийного аппарата данной области знаний. Отдельно утверждается об отсутствии признака необходимости инновационного потенциала в структуре комплексного показателя ЭП.

Подчёркивается необходимость верификации оценки ИП инн для целей расчёта ЭП. Выявлена соподчинённость последовательности элементов ЭП для целей оценки.

\section{ЛИТЕРАТУРА}

1. Заде Л.А. Основы нового подхода к анализу сложных систем и процессов принятия решений. В кн.: «Математика сегодня». — М.: «Знание», 1974.

2. Хайруллин В.А. Оценка инвестиционного потенциала сектора высокотехнологических компаний Российской федерации /В.А. Хайруллин, С.Ф. Сайфуллина, Н.Н. Ривкина //Интернет-журнал «Науковедение», №4(17), 2013.- С.1-12.

3. Головкин Д.С. Актуальность разработки комплексной методики оценки экономического потенциала предприятия // Вестник Ивановского государственного университета. Серия: Экономика. 2015. № 3-4 (25-26). 97-102с.

4. Жигунова 0.А. Теория и методология анализа и прогнозирования экономического потенциала предприятия: монография. - М.: ИД «Финансы и Кредит», 2010. -140 c.

5. Smith, Adam. An Inquiry into the Nature and Causes of the Wealth of Nations. Edited by S.M. Soares. MetaLibri Digital Library, 29th May 2007. Available at: https:// www.ibiblio.org/ml/libri/s/SmithA_WealthNations_p.pdf. Date accessed: 06 Jan. 2020.

6. Ибрагимова Р.С., Головкин Д.С. Методическое обоснование оценки экономического потенциала предприятия // Современные наукоемкие технологии. Региональное приложение. №3 (47). 2016г.

\footnotetext{
(๑ Елшибаев Ракымжан Камытбекулы (rakymzhan.yelshibayev@bk.ru), Даржанова Мунира Шамсутдиновна (mun46@mail.ru), Болатқызы Салтанат (saltab@mail.ru).

Журнал «Современная наука: актуальные проблемы теории и практики»
} 